\title{
How parent relationships could hold the key to managing type 1 diabetes
}

Type 1 diabetes is a lifelong condition that can have of life. Managing it effectively with insulin is key to keeping healthy; however, adherence is often easier said than done, especially with young adults. Prof Cynthia Berg and clinical psychology doctoral studen at the University of Utah are leading pioneering research revealing how family dynamics affect successful management of type 1. Their research provides fresh insights into how relationships are key to living healthily with type 1 and crucially, could shed ligh intervention.
The transition to adulthood can be a challenging. Navigating the
ups and downs of adolescence oth exhilarating and daunting, with friendships, responsibilities and pressures constantly changing as peop transition from school to employment and from living with parents to independence. For young people with type 1 diabetes, these years can be especially tricky. Living with a chronic medical conction can benefit from supportive relationships, relationsh adulthood This period of emergng adulthood is a high-risk time for type 1 diabetes management but as yet, remains an understudied area.

Type 1 diabetes is a lifelong condition that affects 1.5 million people in the US and results in high blood glucose levels because the body cannot make insulin, produced by the pancreas. Insulin allows the body to store glucose from carbohydrates and regulates levels of sugar in the blood. The cause of type 1 diabetes - previously referred to dinger diabetes - is unknown. Untreated it can .

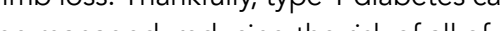
these associ, en mana me intensive and emotionally draining making adherence difficult.

\section{MANAGEMENT OF TYPE 1}

Type 1 diabetes management needs type 1 have to self-administer insulin, changing the frequency and dose of insulin dependent on recent food intake, exercise and circulating blood sugars. Blood glucose levels have to continually be monitored and carefully balanced. Missed medication can cause tiredness, thirst and the build-up of ketones (molecules that are produced by the liver when the body breaks down fat). Too much insulin can also have taken a dose and injting you have cake a dose and inecting again

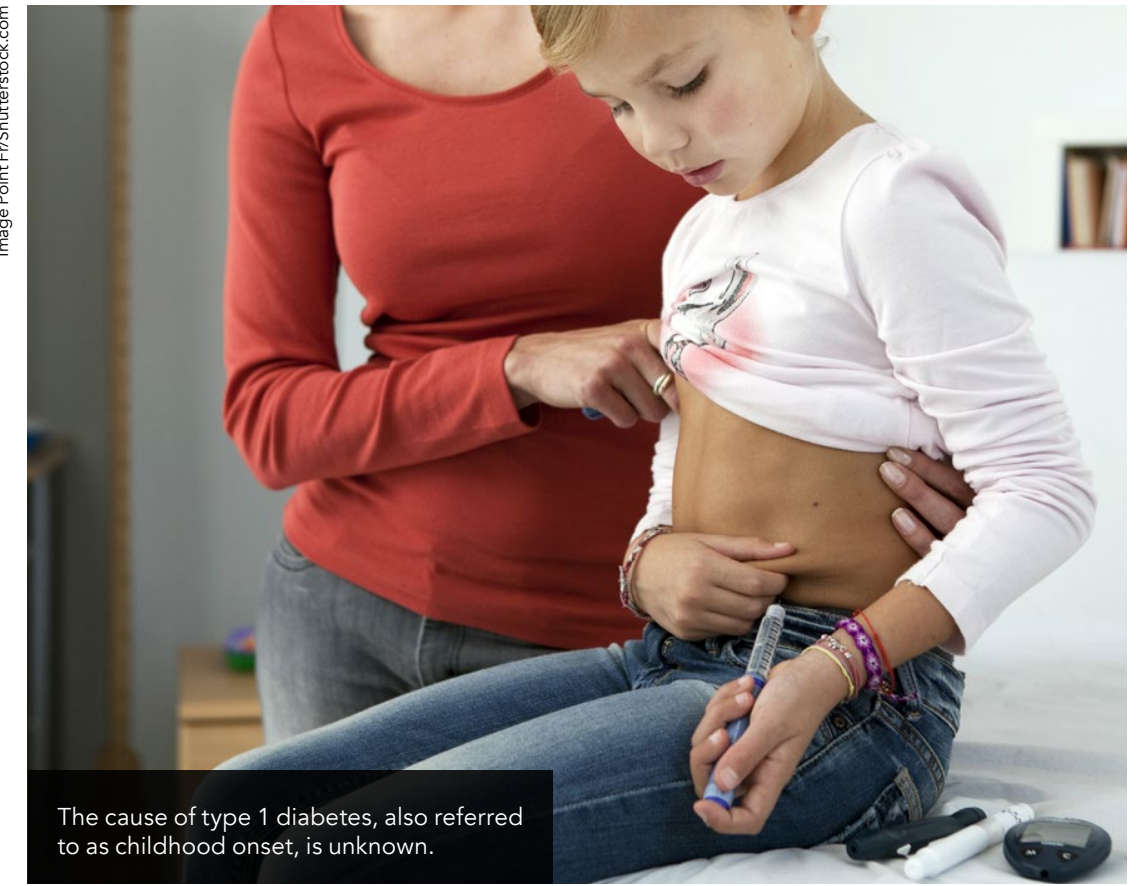

lead to dizziness and even seizures in severe circumstances.

The transition between paediatric and dult care is known to be a risky time for adherence to management regimes, yet much remains unknown about how best to support people in this age group. Constantly achering to self-management behaviours can create distress for adolescents and adults and be difficult to manage alongside transitions such as leaving the family home, going to college, and navigating new social circles. Prof Cynthia Berg, Distinguished Pressorth Psychol C U how young people live with longterm heath conditions, bridging the knowledge gap between adolescen and adult research.

\section{THE SOCIAL NETWORK}

The changing nature of relationships in adolescence is profound as children move towards friendships and are less influenced by parental input. Prof Cynthia Berg studies how family and friendships can influence adolescent management of chronic iliness such as cancers and diabetes. Together with colleagues, she is interested in how young people manage their social context, examining hin parts and fiends can help or hinder diabetes mant observational study at two sites . up for four rears. The findings shed light not only on the role of relationships, but crucially, point to family issues that could be targets for intervention.

\section{PARENTAL INVOLVEMENT}

nts' knowledge about their child's activities around (yically declines. The READY management, measured by levels of disclosure, acceptance, and knowledge of activities, is linked to better values of blood glucose compared with families Fur Furthermore, chidren whose parental year did better than in years when heir parental invent was The findings suggest that a strong foundation of good relationships with parents supports health outcomes. This was especially true for young people. who had lower levels of what is referred to as executive function, an aspect of together with Prof Deborah Wiebe to focus on emerging adulthood. The

This period of emerging adulthood is a high-risk time for type 1 diabetes management but as yet, remains an understudied area.

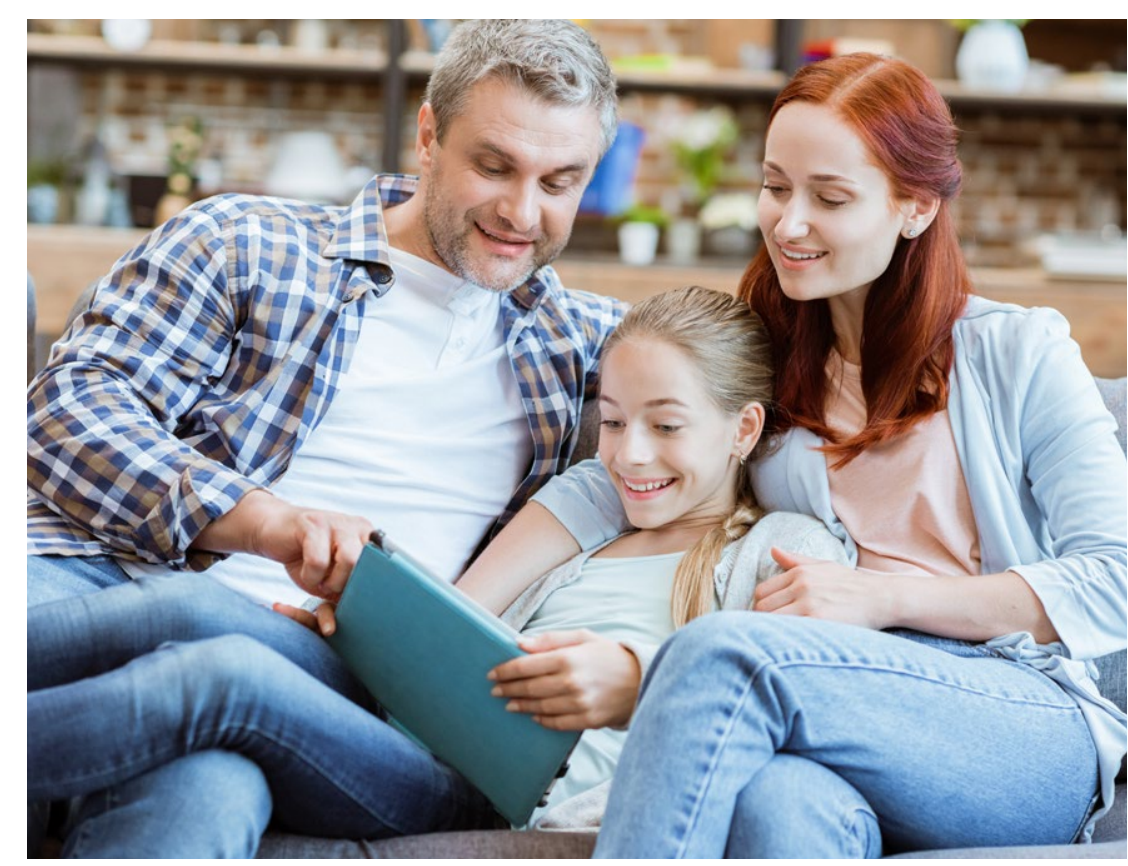


Mothers' Knowledge is beneficial for young adults with Lower Executive Function (EF)

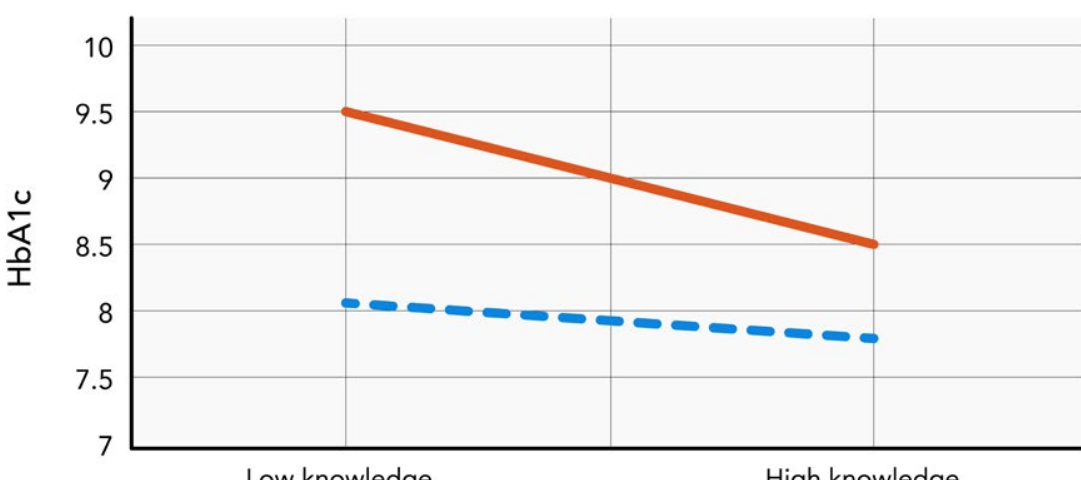

Low knowledge

High knowledge

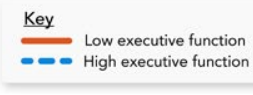

Parental involvement, here depicted as mothers' knowledge about the child's diabetes activities

Family conflict was linked to lower adherence to management and higher values of glucose level, especially where parents report low self-control.

cognition that refers to our ability to those with higher levels of executive function fare better in terms of their plan, switch attention and multit

Staying on top of one's daily self-care requires a high degree of executive time, reducing the risk of complications later in life. High-quality involvement The READY study shows that to lapses in management for those with lower executive function. Identifying make it easier for health professionals to spot those who need greatest support.

\section{TOWARDS INTERVENTIONS}

One aspect of family life, namely conflic over diabetes management, has also been examined in their lab. The analysis led by MaryJane Simms Campbell, a clinical psychology doctoral student at the University of Utah, shows that while family conflict was linked to lower adherence to management and higher values of glucose level, this association was reduced when parents reported higher self-control. These findings support the idea that parents who are more
involved and self-controlled can improve involved and self-controlled can improve Addressing conflict and self-control through psychological therapies can have a positive impact on health.

Paediatric health messaging often emphasises the importance of establishing autonomy during adolescence. However, these findings underline how crucial parental involvement is in diabetes management as their child navigates this changing time. Prof Berg and her colleagues poin out in a recent paper in the Journal of Paediatric Psychology that this could be facilitated by technology, for example, by sharing glucose monitoring data to to the parental knowledge. In contrast READY research shows that connections with parents remain vital duringections period particularly for those with lower executive function.

\section{LOOKING FORWARD}

The findings of the READY study provide a wealth of insight into how family management for emerging adults, underlining the importance of parenta

- involvement. Furthermore, they are developing interventions that can support young adults through text messaging and improving supports from romantic partners, friends, and family during this tricky transition phase. As incidence rates continue to rise, more and more young people will be affected by the burden of fing with this condition, and the quest to

\section{Behind the Research}

R.

Dr Cynthia Berg

E: cynthia.berg@psych.utah.edu people/faculty/berg-cynthia.php @CindyBergLab

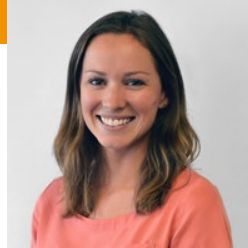

T: +1801916302

Research Objectives

Dr Berg and doctoral student Campbell study how young adults with type 1 diabetes manage their illness and changes in parental involvement.

\section{Detail}

$\begin{array}{ll}\text { Cynthia Berg } & \text { Bio } \\ \text { Department of Psychology } & \text { Dr Cynthia Berg is Distinguished Professor of } \\ \text { University of Utah } & \text { Psychology, Co-Director of the Consortium for }\end{array}$ $\begin{array}{ll}\text { Department of Psychology } & \text { PrCynthia Berg is Distinguished Professor of } \\ \text { Universitit of Utah } & \text { Pychology, co-Director of the Consortium for } \\ 380 \mathrm{~S} \text {. } 1530 \mathrm{E} \text {. } & \text { Families and Health Research, and Dean of the }\end{array}$ $\begin{array}{ll}380 \mathrm{~S} .1530 \mathrm{E} . & \text { Families and Health Research, and Dean of the } \\ \text { Salt Lake City } & \text { College of Social and Behavioral Science at the }\end{array}$ Salt Lake C
UT 84112
USA

MaryJane Simms Campbell is a clinical Science Foundation Graduate Research Fellow, University of Utah.

Funding Maryjane Simms Campbell : maryjane.campbell@psych.utah.edu js_campbe National Institutes of Health, grants
R01DK063044; R01DK092939

\section{References}

- Berg, C.A. W. Wiebe, D.J., Tracy, E.L., Kelly, C.S., Mello, D.,
Turner. S.L.'Butner, J., Munion, A.K. K. Mansfield, J., White, P. Murray, M., and Suchy, Y. (2019). Parental Involvement and Executive Function in Emerging Adults with Type 1 - Berg C. A Wiebe, DJ Suchy Y Turner, S L B B J., Munion, A., Lansing, A.H., White, P., and Murray, M. (2018). Executive function predicting change in typerging adulthood. Diabetes Care, 41(11), 2281-2288. - Butner, J., Berg, C.A., Munion, A.K., Turner, S.L., HughesLansing, A., Winnick, J.B., and Wiebe, D.J. (2018). type 1 diabetes management in late adolescence. Annals of Behavioral Medicine, 52, 29-41. Campbell, M.S., Berg, C.A., and Wiebe, D.J. (2019). management. Journal of Pediatric Psychology, 44(8), Munion, A.K, Butner, J., Kelly, C.S., Wiebe, D.J., Turner,
S.L., Hughes-Lansing, A., and Berg, C.A. (2020). The separation in coordination between social and self regulation for emerging adults with type 1 diabetes. J
Behav Med. Available at: https://www. doi org/101007/ \$10865-020-00134-5 [Online ahead of printt].
Wiebe, J., Berg, C.A., Mello, D., and Kelly, C.S. (2018). Self-and social-regulation in type 1 diabete management during late adolescence and emergin
adulthood. Current diabetes reports, 18(5), 23. Jonathan Butner, PhD, Mary Muchy, PhD, d, MD, Perrin White, MD Large team of graduate students and
postdocs from the READY lab (Amy Hughes Lansing, Alex Main, Tara Queen, Eunjin Lee Baker, Avia Gray, Ascher Munion, Maria Ramirez Loyola, Daniel Mello, Sara Turner), Jessica Mansfield (Project Coordinator) an

\section{Personal Response}

\section{What sparked your interest in young people's diabetes}

Cynthia Berg: I was intrigued by how families solve families regularly solve daily problems with highs and lows in
in MaryJane Simms Campbell: I am especially interested ilnesses. Given the dally challenges associated with managing type 1 diabetes, understanding the psychosocial
impact of the condition for the child and their family is particularly important.

\section{What could such a family intervention look like?}

II As families are still important during emerging adulthood, interventions that keep parents involved in an young adults receive to romantic partners and friends will be important. Further, as family conflict is a normal aspect of adolescence and can, undercontive for codolest that promote working through conflict will be helpful. For example, interventions that teach families strategies to more efeneficial for teens with type 1 diabetes may be manecially emotions, problem-solving skills, and conflict resolution techniques)

II

